\title{
APPLICATION OF BASICS FIXED PROSTHODONTICS PRINCIPLES BY DENTAL PRACTITIONERS IN SAUDI ARABIA
}

\author{
Amal A Shafaei*
}

\begin{abstract}
Objective: To characterize the methods and materials used in fixed prostheses in Saudi Arabia.

Methods: A questionnaire was developed and distributed in 2014-2015 to a simple random sample of 200 dental practitioners and distributed among private and governmental sectors in 12 different Saudi Arabian cities. The questions were designed to provide understanding of the awareness and knowledge of dentists regarding the new materials and modern techniques that exist in the practice of fixed prosthodontics. Completed questionnaires were analyzed in terms of a simple summary statistic.

Results: a total of $86.4 \%$ of the practitioners responded. The majority of respondents reported using porcelain fused to metal as crown and bridge materials. Powder/liquid glass based system to construct fixed prostheses was the method of choice for $69.6 \%$ of respondents. Among those who indicated using direct prefabricated post, $44 \%$ use a fiber glass post. Only $7.9 \%$, however, used Zinc Phosphate cement, while $35.6 \%$ used Resin cement and the majority used traditional glass ionomer cement as a permanent cement.

Conclusion: In Saudi Arabia, there are traditional trends in practice that do not appear to be supported by scientific evidence. The results of this survey demonstrate the importance of integrating evidence-based practice concepts into teaching curriculums, continuous education courses, and postgraduate studies. However, further studies are necessary to evaluate this trend.
\end{abstract}

KEY WORDS: Dental practitioner, Fixed Prosthodontics, Material and techniques.

\section{INTRODUCTION}

Prosthodontics is defined as the branch of dentistry pertaining to the restoration and maintenance of oral function comfort appearance andhealth of the patient by the restoration of the natural teeth and /or replacement of missing teeth with artificial substitutes ${ }^{(\mathbf{1})}$. It is an extremely technique specific branch of dentistry pertaining to the oral rehabilitation of the patient by the practitioner who provides complete dentures, removable partial dentures, fixed partial dentures and various

* Lecturer of Fixed Prosthodontics, Restorative Dentistry Department, Faculty of Dentistry, University of Hail, Hail, Saudi Arabia 
maxillofacial prosthesis also the practitioner must be aware of the biocompatibility and biocompatibility of the prosthesis and techniques which are being used for the patient.

General dental practitioners provide a significant number of indirect restoration and fixed prosthe$\mathrm{ses}^{(2)}$. This is probably due to three principal factors, namely: patients are demanding fixed as opposed to removable prostheses for the replacement of missing teeth; patients are living longer and retaining more teeth; and increasingly indirect restorations are being used to restore damaged and worn teeth to form and function. The recent adult dental health survey demonstrated that the trend towards increasing numbers of adults retaining more teeth is set to continue and it is therefore logical to assume that more fixed prostheses will be both requested by patients and provided by practitioners ${ }^{(3)}$. Against this backdrop practitioners have the opportunity to apply increased choices in terms of materials and techniques many of which have a dubious evidence base. ${ }^{(4)}$

In a recent publication by the Ministry Of Health of Saudi Arabia in 2014, the total number of practicing dentists reached 10150 doctor including 1955 specialist in private sector and 606 in governmental sector ${ }^{(5)}$.

Saudi Arabia is a country undergoing rapid expansion in oral healthcare services. The provision of prosthodontic services is also widespread with a correspondingly strong call among dental professionals to engage in prosthodontic practice Over the years various higher training pathways have been put in place culminating in a situation today in which educational programs of different designs in prosthodontics and in related disciplines coexist at the same institution this environment seemed useful for investigating the possible influence of educational differences on prosthodontics procedures.

In Saudi Arabia there are approximately 4260 practicing dentists who have access to continuous education courses offered by universities and the Saudi Dental Society Approximately $63.6 \%$ of them have access to continuous education in the form of lectures and or hands-on training ${ }^{(6)}$ the aim of this study was therefore to determine the themes (if any) that exist in fixed prosthesis carried out by general practitioners in Saudi Arabia to investigate, by questionnaire, the use and follow the basic principles of fixed prosthodontics including recent materials and techniques.

\section{MATERIALS AND METHODS}

This is a pilot cross sectional study. A questionnaire, based on annual survey of practitioners in the USA by clinical research associates, was designed to seek information about various aspects of current practice in primary dental care ${ }^{(7)}$.

A questionnaire was written and sent to 200 randomly selected practitioners who performed Fixed Partial Denture and are registered with the Saudi Dental Society (SDS) from 12 different cities ( Riyadh, Jeddah, Makkah, Madinah, Tabouk, Hail, Jizan, Dammam, Najran, Skaka, Khober and Khafji). Inclusion criteria included: 1) Any dentist or specialist who performed Crown and Fixed Partial Denture; 2) Dental practice in Saudi Arabia; and 3) Electronic email contact. We excluded answers from dentists outside Saudi Arabia. A selfadministrated questionnaire consisting of 2 sections and 28 questions. A) General questions (Q. 1-5) and B) Basics of Fixed prosthodontics principles related to materials and techniques used (Q. 6-28) as shown in (Table 1)

A pilot questionnaire was given to 7 dentists and prosthodontist to evaluate their comprehension of the survey and the clarity of the questionnaire. Based on the feedback received from the dentists/ prosthodontist, the questionnaire was refined into its final format.

For some questions, participants were asked to choose the answer that best fit their clinical situation when a list of possible answers was given, and if 
they found none of the selections to be suitable, they were permitted to type out an answer of their own. An explanation of the study objectives accompanied the questionnaire; the study ensured confidentiality by not including the names or identification numbers of the participants, hence guaranteeing their anonymity.

TABLE (1) Data collected in the questionnaire

\begin{tabular}{|c|c|c|}
\hline A & $\begin{array}{c}\text { General } \\
\text { Questions }\end{array}$ & $\begin{array}{l}\text { 1-Sex } \\
\text { 2-Years of experiences } \\
\text { 3-Degree of education } \\
\text { 4- City } \\
\text { 5- Job place }\end{array}$ \\
\hline B & $\begin{array}{c}\text { Basics } \\
\text { principles } \\
\text { of Fixed } \\
\text { prosthodontics } \\
\text { related to } \\
\text { Materials and } \\
\text { techniques } \\
\text { used }\end{array}$ & $\begin{array}{l}\text { 6- Taking medical history } \\
\text { 7- Taking dental history } \\
\text { 8- Taking a preoperative x-ray } \\
\text { 9- Getting index before } \\
\text { preparation\& study cast. } \\
\text { 10- Type of restoration used for } \\
\text { Fixed prosthses } \\
\text { 11- Method for ceramic } \\
\text { construction } \\
\text { 12- Position of finish line } \\
\text { 13- Type of finish line } \\
\text { 14- Type of ceramic used } \\
\text { 15- Type of impression material } \\
\text { 16- Type of impression technique } \\
\text { 17- Type of gingival retraction } \\
\text { method if used } \\
\text { 18- Making temporary restoration } \\
\text { 19- Type of temporary restoration } \\
\text { used } \\
\text { 20- Type of temporary cement } \\
\text { 21- Using post \& core system } \\
\text { 22- Type of post used } \\
\text { 23- Type of core material } \\
\text { 24- Duration between impression } \\
\text { 25- Making try-in for checking and } \\
\text { 26- Management of problem during } \\
\text { 28- Type of permanent cement }\end{array}$ \\
\hline
\end{tabular}

\section{Data analysis}

Online questionnaire were distributed using the web interface " Google drive doc". To avoid duplication, we asked the participant to fill out a single questionnaire. In order to improve the participant response rate to the survey, resent the email in 2015 to remind them to submit their answers. The completed questionnaires were eventually collected from 165 dental participants.

Completed questionnaire were entered into a computer and analyzed using SPSS version 20.0(SPSS, Inc, Chicago, IL, USA). The P value was considered significant if it was $<0.05$.

\section{RESULTS}

One hundred and ninety-one questionnaires were distributed, of which 165 were returned (response rate:86,4\%) including questions regarding general questions and basics principles of Fixed Prosthodontics related to materials and techniques used. Most of dentists were females $(62,8 \%)$ while the dentists male were $(37,2 \%)$.the majority of participants reported having a bachelor's degree $(59,7 \%)$ while $(29,3 \%)$ had master degree and (11\%) had $\mathrm{PhD}$ in the prosthodontics field. Of these, approximately $35 \%$ had been in practice for less than 5 years were $39,8 \%$ between $5-10$ years and the remaining $(25,1 \%)$ for more than 10 years. Approximately $57,6 \%$ of the participants practiced in private sector, $28,8 \%$ in the governmental sector, and $13,6 \%$ in the academic sector.

Ninety-eight percent of respondents reported always taking a medical history before start work, while $2 \%$ were concerned about the patient's medical history only if there were signs/symptoms of systemic disease, and the same rate for taking the dental history.

Most respondents $(61,8 \%)$ took preoperative $\mathrm{x}$-ray before preparation, while $(30,4 \%)$ did not took and the remainder were took $\mathrm{x}$-ray when case needed. 
Half of respondents were took index before preparation $(48,7 \%)$ while the other half didn't take $(47,6 \%)$.

Dentists were most commonly using porcelain fused metal $(59,7 \%)$ and all ceramic $(39,8 \%)$ as crown and bridge materials, most of dentists who used all-ceramic materials had no advanced dental certificate (master or PhD). Figure (1). This difference was significant, $P=0.000$.

Fifty-three percent of the respondents preferred to construct ceramic crown and bridge using powder/liquid glass based system, $69.6 \%$ of them have bachelor degree while the reminder have a high education certificate . $25 \%$ used pressable blocks of glass-based system, and the remainder used CAD/CAM system. It was apparent that the practitioners have high education ( master or $\mathrm{PhD}$ ) used more CAD/CAM system than people have bachelor degree and this difference was significant, $P=0.000$. Figure (2).

Approximately half of the respondents $(47,6 \%)$ prepared finish line sub-gingivaly, $(29,3 \%)$ supragingival while the $(23 \%)$ put finish line equigingival.

Fifty-nine percent of respondents prepared chamfer finish line while the remainder $(38,2 \%)$ prepared shoulder finish line.

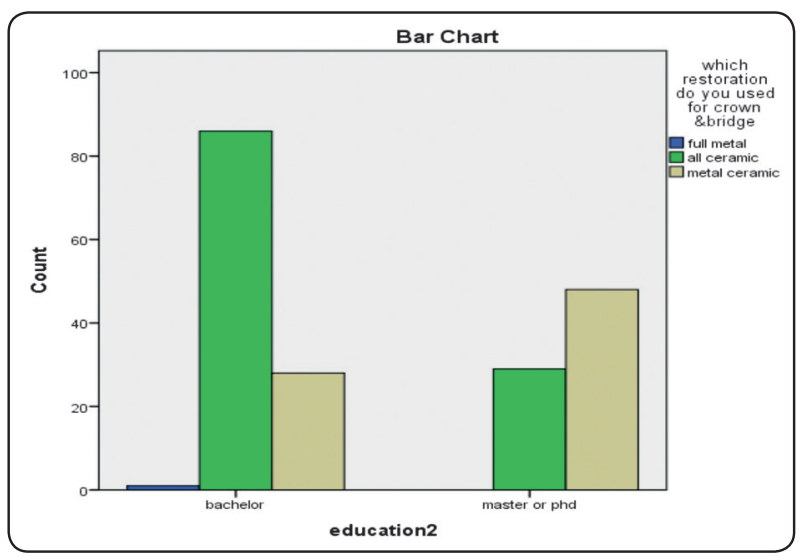

Fig. (1): Type of restoration used for fixed prostheses.
Silicone based impression materials $(70,2 \%)$ were the most preferred impression materials by the practitioners in this study. Polyether $(15,7 \%)$ and alginate $(14,1 \%)$ impression materials were also used but less frequently.

Most of respondents $(69,1 \%)$ used retraction cord for gingival retraction, while the $(27,7 \%)$ used gingittage (tissue troughing technique).

Approximately ninety- seven percent of respondents made a temporary crowns. Of these (45\%) used custom made crown, while $(47,6 \%)$ preferredprefabricated temporary crown.

Zinc-oxide eugenol luting cement $(62,3 \%)$ was the most used temporary cement by the practitioners in this study. $\mathrm{CaOH}(24,1 \%)$ and $\mathrm{ZnPh}(11 \%)$ temporary cement were also used but less frequency.

In case of endodontically treated teeth most of respondents $(91,6 \%)$ use post and core system before fixed prostheses construction.Direct prefabricated post of fiber glass $(44 \%)$ and metal post $(36,1 \%)$ were preferred by a majority of the practitioners. Indirect custom made post $(18,3 \%)$ were prescribed less frequently with very few practitioners not placing posts. By using statistical analysis Chi testpoints to more practitioners with high education certificate (master or $\mathrm{PhD}$ ) preferring to use fiber glass post than practitioners with bachelor degree. This difference was significant. $(P=0.000)$ Figure (3)

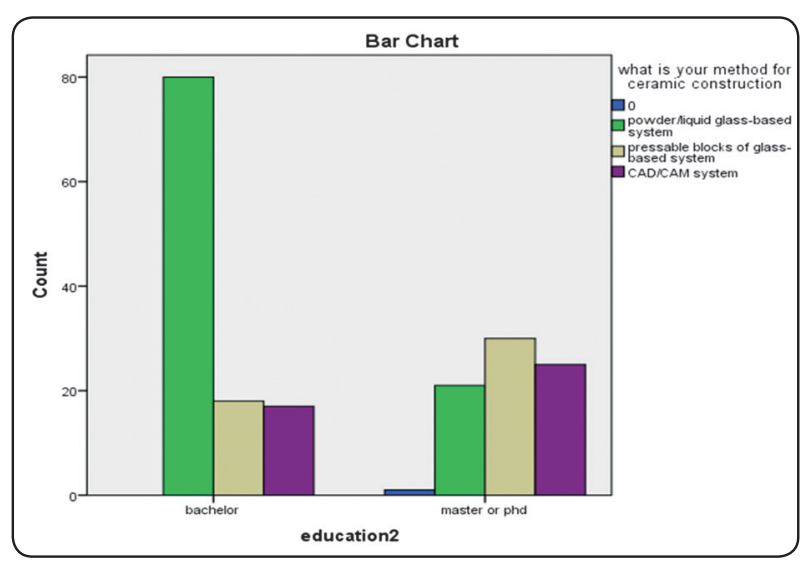

Fig. (2): Methods for ceramic construction. 


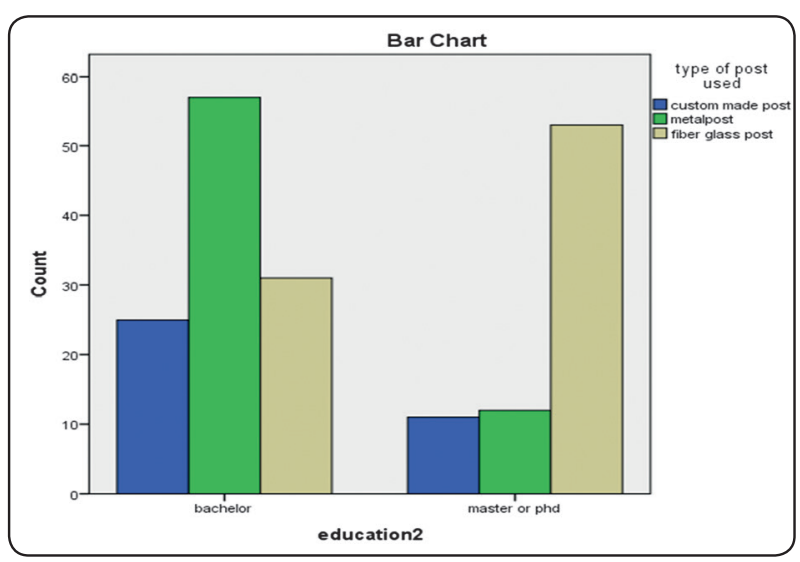

Fig. (3): Type of post used.

The majority $(67,5 \%)$ of practitioners in this study used composite for core build up of non vital teeth, amalgam $(19,4 \%)$ and ceramic $(12 \%)$ as preferred alternatives.

Most of respondents(76,4\%) were delivered the prostheses after duration between 2-7 days, while $(8,9 \%)$ after 2 days or less, and $(14,7 \%)$ after more than 7 days.

Sixty- two percent of respondent make a tryin, while $(38,2 \%)$ not preferred. Near half of the dentists were cementing the prostheses temporary for trail.

Luting cement based on traditional glass-ionomer cements were used to cement porcelain fused metal reconstructions by a majority $(56,5 \%)$ of the practitioners in this study. Resin compsite $(35,6 \%)$, $70 \%$ of them have high education certificate (master and $\mathrm{PhD})$. So, there is significant difference, $P=$ 0.000.Figure (4).

Zinc phosphate $(7,9 \%)$ cements were used by a significant number of practitioners.

In case of improper fitting fixed prostheses approximately half of respondents $(45,5 \%)$ return the restoration to the lab as a trial for solving the problem, while $(31,4 \%)$ of them try to solve it by themselves, and the remainder $(23 \%)$ remake the prostheses.

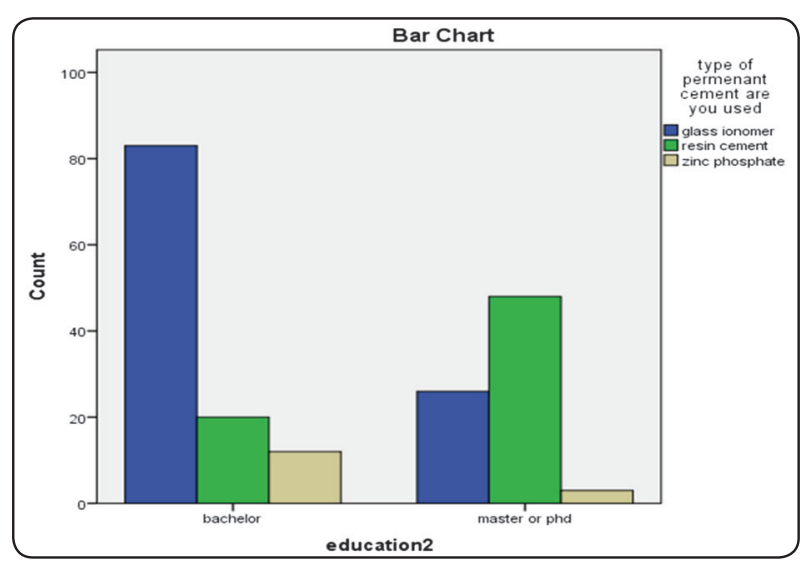

Fig. (4) Type of permanent cement used.

\section{DISCUSSION}

The specialty of fixed prosthodontics has witnessed some major developments over the last ten years. The totality of these advances has resulted in more predictable results on the prosthetic and esthetic levels. With consideration of these advances, emphasis on teaching tactics will promote some of the major advances that pertain to general practitioners. Ideally, there should be a trend in which dentists take advantages of all ceramic restoration, CAD/CAM construction technique, fiber post in case of endodontics treated teeth and resin cement for permanent cementation of ceramic restorations.

In this study we wanted to establish baseline data regarding the various aspects of fixed prosthesis as practiced by dentists in Saudi Arabia. Then, based on these results, we wanted to determine if there are any trends in terms of the practice of various aspects of fixed prosthesis.

The percentage of the respondents using metal ceramic restorations was $60 \%$. Porcelain fused to metal was most commonly used material in crown and bridge which was similar to other studies. ${ }^{(\mathbf{8 , 9})}$ Among the construction techniques, powder/liquid glass based system was the most widely used, followed by pressable blocks of glass-based system. 
CAD/CAM systems are expensive and currently in Saudi Arabia, practitioners seem to prefer to use a laboratory to produce their restorations despite the high success rates being reported. ${ }^{(10)}$ the results of this study support this, with $22 \%$ of restorations produced with the aid of CAD/CAM.

It is accepted that addition cured polyvinylsiloxane along with polyether are the most accurate impression materials, giving predictable results in the hands of the majority of practitioners. ${ }^{(11)}$ it was reassuring that the majority of the practitioners in this study routinely used an addition silicone impression material yet somewhat surprising that relatively few practitioners used polyether materials routinely. Polyether impression materials are very rigid and usually recommended for implant cases, they are somewhat difficult to disinfect, which probably explains the small use recorded in the study. ${ }^{(12)}$

If post and core is clinically indicated, direct placement of a prefabricated post and direct core build-up is to be preferred. However, the practitioners in this study frequently used this technique. This is surprising given that direct posts and cores save the patient a visit and at the same time appear to have a reduced risk of fracture when directly placed prefabricated posts are used with direct resin composite core materials. ${ }^{(13)}$

Composite was the principle choice of the practitioners in this study for the core build-up of endodonticaly treated teeth. Significant numbers of practitioners would appear to use light-cured resin composite and traditional glass-ionomer cement as direct core material..$^{(14)}$

Twenty years ago, the use of adhesive resin composite luting agents to cement dental restorations was not common, resin cements now account for a growing proportion of cement use, the reasons for which include their better mechanical properties compared with conventional luting agents. ${ }^{(15)}$ In this study $(35,6 \%)$ of practitioners used resin composite cement. The American Dental Association ${ }^{(16)}$ has defined Evidence-Based Dentistry as "an approach to oral health care that requires the judicious integration of systematic assessments of clinically relevant scientific evidence, relating to the patient's oral and medical condition and history, together with the dentist's clinical expertise and the patient's treatment needs and preferences." This approach encourages the use of the latest information rather than a reliance on techniques, materials and treatments learned years earlier. Relevant to the findings of this survey, implementing the Evidence-Based Dentistry approach might prove to be an ideal approach by which to promote the theme of practices that are based on evidence in contrast to those that are not. Additionally, it might be an effective way to teach the process of critical appraisal to those graduates and practitioners who appear to be deficient in its application.

Continuing dental education programs in the field which can highlights the recent materials and methods can help to improve the practitioners clinical effectiveness and quality of the treatment rendered to the patients. It may also be necessary to emphasize strongly the basic prosthodontics principles in the undergraduate teaching curriculum.

There were a few limitations to our study. The study consisted of a convenience sample of practitioners with email and who responded to our survey and results relied on their responses without clinical evidence. However, this is a pilot study and we hope in the future to design a study with a sample representing the entire country.

\section{CONCLUSION}

This report has described fixed prosthodontics as currently practiced by dentists in Saudi Arabia:

- The majority of dental practitioners have followed the basics principles using recent materials and techniques during fixed prosthodontics, especially who have high education certificate. 
- It was determined that some practitioners are using outdated techniques and materials with no evidence of clinical effectiveness. However, further studies are required to evaluate the trend.

\section{Suggestion for further studies}

The results of this survey to identify deficiencies and to obtain baseline data to develop postgraduate prosthodontics courses and continuous education workshops to promote skilled health professionals in the prosthodontics field. However, further studies are necessary to evaluate this trend.

\section{REFERENCES}

1- Blarcom V, Clifford W. The glossary of prosthodontics terms. Journal of Prosthetic Dentistry 1999; 81:44-106.

2- Annual Digests of Statistics(2000-2002). Eastbourne: Dental Practice Board.

3- Richards D, Lawrence A, Sackett DL. Bringing an evidence base to dentistry. Comm Dent Hlth 1997; 14:63-65.

4- Brunton P A, Wilson N H F. preparations for porcelain laminate veneer in general dental practice. Br Dent J 1998; 184:553-556.

5- Saudi Ministry of Health. Annual report. Accessed (Dec 2014) at: http://www.moh.gov.sa/statistics/year/chapters.html.

6- Saudi Dental Society. Annual report. Riyadh: King Fahad National Library; 2006.

7- Burke F J, Wastell D G, Cheung S W. Glove use in clinical practice: A survey of 2000 dentists in England and Wales. Br Dent J1991;171:128-132.
8- Hatzikyriakos A, Petridis HP, Tsiggos N, Sakelarious S. consideration for services from dental technicians in fabrication of fixed prostheses: a survey of commercial dental laboratories in Thessaloniki, Greece. J Prosthet Dent 2006;96:362-366.

9- Baumann B, Pai WH, Bennani V, Waddell JN. Dental alloys used for crown and bridge restorations by dental technicians in New Zealand. N Z Dent J 2010;106:43-49.

10- Martin N, Jedynakiewicz N M. clinical performance of CEREC ceramic inlays: a systemic review. Dent Mater 1999; 15:54-61.

11- Chee W W, Donovan T E. polyvinylsiloxane impression materials: a review of properties and techniques. J Prosthet Dent 1992; 68:728-732.

12- Johnson G H, Dernnon D G, Powell G L. accuracy of elastomeric impressions disinfected by immersion. J Am Dent Assoc 1988;116:525-530.

13- Blignaut J B, Grobler S R. the resistance to deformation forces of endodontic posts manufactured from six different materials. J Dent Assoc S Afr 1995;50:363-366.

14- Piwowarczyk A, Ottl P, Lauer HC, Buchler A. Laboratory strength of glass ionomer cement, compomers and resin composites. J Prosthodont 2002; 11:86-91.

15- White, S N, Yu,Z. physical properties of fixed prosthodontics resin composite luting agents. International Journal of Prosthodontics 1993;6;384

16 - American dental association (2003) Policy Statement on Evidence-Based Dentistry. Accessed (Dec2013) at : http://www.ada.org/prof/resources/positions/statements/ evidencebased.asp. 